\section{Evaluation of a new}

Short-Project Based Learning (PBL) method in an engineering 1st year programme

\section{Junior Nomani ${ }^{\mathrm{a}}$}

Guy Littlefair ${ }^{b}$

Auckland University of Technology

Teaching approaches in engineering undergraduate programmes develop over time, to accommodate latest industry demands and technological needs, to incorporate new technologies in teaching and learning, or it adapts to become more relevant to climatic changes in cultural and societal shifts ushered by the next student generation.

This study presents a new developed approach towards traditional Project Based Learning (PBL) in an engineering undergraduate 1st year program. PBL (Project Based Learning) also known as Problem Based Learning is a pedagogy which organises learning around projects. The project must involve some development of new understanding or new skills within a space occupied by group of students solving the task and teacher providing feedback. The duration of a PBL project spans traditionally from a few weeks in a semester to a full teaching year.

The new approach presented in this study, was to implement a PBL project in an engineering paper which ran its full duration, start to finish in half a day. Shortened PBL projects offer an advantage of maintaining student engagement and cognitive impact throughout the entire project duration. A task often difficult to maintain by students during a normal length project.

This study presents the evaluation of a short PBL project delivered in a 1st year undergraduate engineering programme. In the project, students were provided a physical space to tackle sustainable re-design of disaster-aid relief items and were also given access to interactive $3 \mathrm{D}$ visualisation technology known as CAVE environment as a design development tool. This study evaluates the effectiveness of short PBL projects as a teaching approach and impact on student engagement.
KEYWORDS
Project-Based-Learning, engineering, CAVE 